\title{
The Emotional Politics of Educational Leaders in Higher Education Institutions: A Discursive Perspective
}

\author{
Kiran Hashmi * $\quad$ Ismail Saad ${ }^{\dagger} \quad$ Margaret Madden ${ }^{\ddagger}$
}

\begin{abstract}
Higher Education Institutions (HEIs) are run under a set hierarchy of executive, operative and administrative levels of educational leaders with a prescribed pattern of processes and functions. A variety of diverse tasks with varied complexities are assigned to the educational leaders of all levels which are expected to be completed within the set time frame. Under such situations, the emotions of the educational leaders play an important role in helping them perform their tasks and achieve the set goals. The current study highlights the elements of educational leaders' emotions' interplay in institutional functioning, emotional relationships between educational leaders and colleagues, their struggle for supremacy over colleagues and micro-politics of Educational Leaders' emotions within their institutions. The study encompasses a combination of five sub-themes that highlight dynamics of emotions and the politics at play in educational leaders' lives. These sub themes are based on the unresolved issues in the approaches of Educational Leaders' emotions including the relationships between emotions and rationality, emotional programming and controlling, emotional denial and sublimation, emotional humanism and behaviorism, and the relationship between emotions and leadership styles. The data for this study were collected through 12 structured interviews with educational leaders of public and private sector HEIs of Sindh. The results indicated the significance of micro-politics of educational leaders emotions in HEIs for its effective functioning. Five themes highlighting emotional micro politics of educational leaders emerged from the thematic analysis: (a) rationality versus emotionality (b) perceived and displayed emotional displays (c) state of emotional denial (d) behaviourist and humanist emotions (e) programmed and controlled emotions. The educational leaders try to maintain a balance between the psychological, social, emotional and political aspects of leadership within HEIs. Their emotions have been marginalized and considered as barriers in the process of effective institutional functioning. Rationality is given a preference over emotionality and its utilization is considered to be a myth. In addition, the research increases knowledge about how Educational Leaders learn to negotiate emotionally intensive situations and use various strategies in the emotional micro-political context of their work within the HEIs.
\end{abstract}

Keywords: Higher education institutions, emotions, educational leaders.

\section{Introduction}

This study is situated in the Sindh's higher education (HE) context where in recent decades the rapid pace of ongoing change in education have effected significantly on higher education institutions (HEIs) and their educational leaders. In educational institutions, leaders are appointed employees whose responsibility is to strive to create a positive change in

\footnotetext{
*Notre Dame Institute of Education, Email: kiranhashme@gmail.com (This research is a part of PhD thesis).

$\dagger$ Iqra University, Pakistan.

$\ddagger$ Australian Catholic University, Australia.
} 
their particular institution. The leaders work with the academic and administrative staff to improve the educational processes operating in the institutions through their management and administrative tasks as well as advancing and improving educational systems, policies and practices. They are usually employed as an administrator with additional roles such as department chair or academic dean. The educational leader has an influential role in inspiring, motivating, affirming and challenging or extending the practice of staff. The staff is motivated enough to achieve their goals. In educational institutions, the educational leaders encounter various events where they can become emotionally charged and display certain emotions which are either effective or harmful for their institutions' functioning (Bottoms \& Schmidt-Davis, 2010). Whether the involvement of emotions in educational leaders' day to day professional endeavor is helpful or affecting the performance of the institution, is the question which this study strives to answer.

Wright (2012) highlighted that emotions play an important role in the personality development of an individual. Aguilera-Ontiveros and Contreras-Manrique (2006) stated that the study of emotions and the emotional behavior of groups in institutional contexts have been gaining relevance in organizational studies since the 1980s. The importance of studying emotions in workgroup settings derives from the evidence that members' behavior in an organization varies according to their emotional condition. They turned attention towards the utilization of emotions for institutional functioning finding that, the presence of emotions in individuals need to be utilized effectively by the leaders, if they wish to attain the desired goals. They further stated that visionary leaders incorporate the emotions of the staff in a more effective manner than those who do not care about human behavior. Franz (2015) stresses the dynamics of emotions while stating that the concept of emotional utilization proposes that emotions act in an interactive and integrated way. Leaders can solve technical problems far easier than human problems in their personal, home and professional lives while utilizing their emotions. If educational leaders take an account of their emotions and of their staff at the workplaces, it is expected to have better institutional functioning. Foo (2011) argued that emotions may affect the evaluation of any institution. Cognition plays a central role in the processes of an institution. However, if emotions get involved, the processes may get affected but the desired goals can be attained as expected. Emotions in the workplace influence a number of critical cognitive tasks including information processing and decision-making. Moreover, the effect of emotion on these operations is often emotion-specific, therefore, leaders may need to learn how to manage the staff's discrete emotions and not just react to general effects. It is imperative that leaders understand the differential effects of discrete emotions and also be prepared to help staff manage emotions accordingly for institutional development (Thiel, Connelly, \& Griffith, 2012).

In recognizing the importance of leaders' emotions for the effective functioning of HEIs, the current study aims to focus on an aspect of the psychodynamics of leadership that has not been extensively investigated in Sindh. It is the relationship between leaders' emotions and institutional functioning, the latter of which can be understood differently through an approach that recognizes and includes the role that leaders' emotions play in the working of an institution. The examination of the psychodynamics of educational leadership in higher education institutions through the involvement of leaders' emotions 
in effective institutional functioning, leadership styles, skills and approaches will contribute to the existing literature on educational leadership. The focus of this study is the relationship between leaders' emotions and institutional functioning in the selected public and private higher education institutions in Sindh.

Till date, studies have been carried out on the interplay of emotions and how they affect or assist educational leaders in institutional functioning. However, it is not enough that educational leaders only show consideration for emotions and their social and institutional dimension. Within HEIs, emotions are a symbol of control and a mode of political resistance. Emotions matter in educational leadership because leaders, academic and administrative colleagues, and students understand and enact their roles through displayed emotional expressions. One of the essential difficulties confronted while building up the conceptual framework for understanding the flow of educational leaders' emotions in HEIs was that there were progressively few occurrences in an individual ordeal. Rather, it is critical that analysis of educational leaders emotions' start with the social settings within HEIs. It can likewise be deceiving on the off chance that Educational Leaders don't recommend from the beginning how and why emotions include political and sociocultural distance. The present paper reports the results of a qualitative study using the emotions and institutional functioning of educational leaders as a lens of analysis. This implies that the investigation looks at how the educational leaders' emotions within HEIs are evoked, communicated and utilized in different institutional functioning approaches.

\section{Literature Review}

The study is based on the basic philosophy of Freud's individual and institutional psychodymanism. The psychodynamic approach to leadership has its roots in Freud's development of psychoanalysis (Fotaki, Long, \& Schwartz, 2012). The psychodynamic approach places emphasis on leaders obtaining insights into their personality characteristics and understanding the responses of colleagues based on their personalities. Leaders also encourage colleagues to gain personal insight, so that they learn to understand their reactions to the leader and others around them. Important concepts in the psychodynamic approach to leadership include family origin, individualisation, dependence and independence, repression and shadow self. Leaders are more effective when they have an insight into their own psychological makeup, and from a similar perspective, understand their colleagues (Herre, 2010). This points to an important aspect of leadership that recognizes the significance of past experiences, the unconsciousness, emotions, self-understanding, personality types, the relationship between the leaders and their colleagues, and the emotional transaction and communication between and among people (Groenendyk, 2011). To facilitate the procedures of having individuals obtain insight and determine their individual needs and the patterns of their emotional reactions to others becomes a leadership imperative.

Berezin (2002) contend that most educational institutions use the theoretical insights of behaviorism and humanism in order to understand concepts of motivation, leadership, institutional structures and development which create the impression that an educational 
institution is a conscious, mechanist, predictable, uncomplicated and easy to understand construct. Contrary to Greyvenstein and Cilliers (2012), Arias, Higuita, and Castrilln (2010) stated that people working in an educational institution, even after serving for years, do not understand the work environment and complain about not being aware of the deeper meaning of their institution. This develops a feeling of being ineffective, uninformed and helpless in situations such as staff or faculty meetings, team building and institutional identification events and programmes. To address this issue, exposure to the psychodynamics of the educational institution can foster a deeper knowledge and understanding of its dynamics and help acquire the skills to interpret the unconscious behavior of groups, teams and the institution as a whole (Almohammad, 2016).

Psychodynamic thinking to be recognized as a relevant and important approach for effective functioning of educational institutions. It is an area of performance about which most educational leaders are often ill-informed. The psychodynamic approach specifies that each educational institution has its own life which is conscious and unconscious, with subsystems relating to and mirroring one another (Fisher \& Byrne, 2012; Bradbury-Jones, Coleman, Davies, Ellison, \& Leigh, 2010). The study of these unconscious behaviors and dynamics leads to a deeper understanding of the processes and functions of the institution and can facilitate institutional change through consultation among leaders and colleagues. The psychodynamic thinking within institutions develops a lateral view to the rational and economic views on work and posits that the services rendered by both the leaders and their colleagues are simultaneously painful and pleasurable activities.

Emotions in the workplace play an important role in how an institution communicates within itself and to the outside world. Events at work have an emotional impact on both employees and employers, the consequences of which have substantial significance for individuals, groups, and society (Durlak, Weissberg, Dymnicki, Taylor, \& Schellinger, 2011). Experiencing positive emotions helps employees obtain favorable outcomes, while conversely, the occurrence of negative emotions increases the predictability of workplace deviance and how the outside world views the institution (Shen, Wang, \& Shen, 2009). According to Srivastava, Tamir, McGonigal, John, and Gross (2009), emotions are associated with specific events or occurrences, and they disrupt the thought process through their intensity. Therefore, the recognition and management of the emotions are important factors in smooth operations of institutional life. It becomes crucial for leaders and colleagues within any institution to create a publicly observable and desirable emotional display as part of functioning in any position (Namkoong, Fung, \& Scheufele, 2012).

Educational leaders' self-reported emotions within their institutions serve as a source of imperative data to be used in organizing the requests of the institution. At the point when leaders understand that their emotions created by low need requests are meddling with the more pressing requests, their capacity to effectively deal with those emotions will facilitate effective functioning.

In HEIs in Sindh, it has been observed that emotional exchange between educational leaders and colleagues is covertly undertaken in the official procedures and processes and less emotional contact is displayed. Emphasis is given more on the procedural processes and decisions and actions are made in alignment with them. Rules are followed rigidly and personal connections and relationships are kept hidden. There is also a lack of litera- 
ture that describes this relationship of emotional exchanges between educational leaders and colleagues. The undertaken study is an attempt to explore this relationship in the light of the institutional procedures driven and designed by the higher authorities.

Emotions can be a reason of providing leaders with information about difficulties and opportunities. Leaders who perceive their emotions and can determine their causes are most often able to determine when those emotions are linked to opportunities, problems or proposed courses of action and use them as sources of information in the process of making decisions. By knowing their emotions and their underlying foundations, leaders can adequately utilize emotional contribution to their work execution. Leaders' awareness of their emotions not only assists in managing them, but also supports in adopting an attainable approach to problems, considering alternative situations, and avoiding firmness and its effects in their workplaces. Task orientation, decision making and human relations within an institution can be fostered when leaders strategically display the required emotions for the effective functioning of their institutions.

The purpose of this qualitative study is to explore how educational leaders' experience and their emotions play a role in the institutional functioning of their HEIs. This study is significant as the current literature is void of describing the interactivity between these two important entities within the higher educational environment.

\section{Methodology}

A qualitative strategy was chosen to help navigate this investigatory effort. A declaration regarding how a researcher views knowledge strategically motivates the research and guides every aspect of the study from question to conclusion.

The researcher conducted a discursive reading of the data from 12 structured interviews with male and female educational leaders of six public and private sector universities of Sindh. The study examined the emotional talk, word usage and responses of educational leaders and investigated how the notion of emotions is taken, constructed and utilized by them in institutional functioning approaches. Methodologically, the analysis is rooted in discursive psychology which is applied in terms of how educational leaders describe and invoke emotions in their talk about institutional functioning (Koval, Butler, Hollenstein, Lanteigne, \& Kuppens, 2015).

\section{Target Population}

In this study, targeted population refers to all leaders of all the three levels, i.e. the executive level, the administrative level and the operational level of the HEIs of the public and private sector in Sindh. Findings may not be generalized to the leadership of the HEIs of the entire country. It is due to the fact that although the HEIs are located in every part of Pakistan, only the selected public and private sector HEIs of Sindh were selected as the sample. 


\section{Sample}

The study consisted of three main groups of subjects for qualitative data: 4 leaders of the universities serving at the executive level of the institution, 4 participants from the administrative level of the universities and 4 participants from the operational level of the institutions from the universities within Sindh were selected. The subjects selected for qualitative data collection were based on selective purposive sampling as it serves the purpose and objectives of the researcher of discovering, gaining insight and understanding into a particularly chosen phenomenon (Fraenkel, Wallen, \& Hyun, 1993).

For the sample of this study, three public sectors universities and three private sectors universities offering social sciences and awarding degrees of bachelors, masters and doctorate degree programs were selected from the target population.

For the purposes of the current research, educational leaders refers to the executive, administrative and operative level designated employees assigned to lead the administrative and academic machinery of the universities according to the rules and regulations designed by the relevant authorities. The study participants possessed the following characteristics. The academic qualification of all the research participants serving the first (executive) level was a doctorate degree, and they were designated as professors with a service experience of 5 years as an executive leader. The research participants serving as the second (administrative) level leadership of the institution also had a doctorate degree and the designation of associate professor or assistant professor with a service experience of 5 years as an administrator. The research participants serving the third (operational) level of the institutions possessed a Masters/M.Phil. degree, with the title of lecturers and a service experience of 5 years as an operational leader. The selected sample was taken from the HEIs that offer social sciences degree programs and have departments of education particularly.

\section{Design}

The topics covered by the interview schedule were informed by the literature review. The questions covered a range of topics from the general to the specific. The topics addressed included participants' perception of their role as leader, the impact of gender (if any) on that role, their positive and negative personal emotional responses to significant events, emotional support in their leadership role and managing their personal well-being.

Pilot study was done to highlight valid and reliable items to improve the interview questions. Interview items were checked for flow, comprehensibility, and practicality. Results from the pilot study were utilized to conform the interview items, redesign interview protocols, and enhance the comprehension of directions of the study.

Structured interviews were selected for this study. The structured interviews supported beneficial discussions designed to enhance transparency and trust within the researcherrespondent relationship. In structured interviews, a list of predetermined questions was asked from the participants on the relationship between educational leaders' self-reported emotions and institutional functioning approaches. For the collection of qualitative data, a total of 12 in-depth interviews were conducted and audio recorded. 


\section{Findings}

The thematic analysis of the data produced the following key themes.

\section{Micro-politics of Emotions / Micro-politics of Educational Leaders' Emo- tions within Institutions}

This theme is a combination of five sub themes that highlights the contradictions in how educational leaders perceive and display their emotions within their institutions. These contradictions have generated insights into the dynamics of emotions and the politics they play in educational leaders' lives. There are unresolved issues in the approaches of leaders' emotions including the relationships between emotions and rationality, emotional programming and controlling, emotional denial and sublimation, emotional humanism and behaviorism, and relationship between emotions and leadership styles.

\section{Rationalism versus Emotionalism within Institutions}

HEIs support the idea that ideal professionalism is more rational and mechanical than emotional. In order to maintain a professional and appropriate decorum, the educational leaders continuously deny or suppress the involvement and expressions of emotions in their professional lives. According to the data, there is a common perception of the educational leaders and their colleagues that emotionality of the educational leaders within their institutions is a myth to their rationality. The idea here seems to point towards educational leaders' emotionalism within their institutions as being destructive, cumbersome and potentially leading to irrationality.

The data highlighted another perception of educational leaders regarding their use of emotions and its relation with rationality which was that there is a hidden connection between educational leaders' emotions and leadership skills and abilities that engage them and their colleagues in professional endeavors within institutions. In the words of Interviewee 2 , decision making is a rational process, it does not require any emotions. The emotional relationship educational leaders and colleagues experience are influenced by the seniority, experience, skill and support of the educational leader. In both the public and private sector HEIs of Pakistan, Educational Leaders enjoy power and authority over their colleagues and pretend to be rationalist and mechanical by hiding their emotional sides to suppress the colleagues. Interviewee 1 asserted that for goal orientation, the task is to be achieved. The subordinates have to follow the commands of the boss. The philosophy of 'yes boss' applies in our universities.

Educational leaders with various leadership styles and skills use their emotions skillfully to get the work done. Those HEIs that have succeeded in promoting an emotionally collaborative culture among educational leaders' colleagues, are performing better in every respect as compared to those who have not accepted the importance of emotional interchanges between the employees. In the words of Interviewee 3 a great leader is one who changes his style according to the changing situation. His emotions help him in adopting the style required. In Sindh's university context, it is rare to find the acceptance of emotional in- 
terchanges among educational leaders and colleagues. In almost all the responses which the educational leaders have shared, almost everyone from executive, administrative and operative levels have highlighted the importance of emotionalism, yet giving preference to rationalistic and mechanistic approaches for effective institutional functioning.

According to educational leaders, rationalism takes a lead over emotionalism, as the bureaucratic and hierarchical administrative structures of the HEIs do not allow them to give enough space to experience emotional interchanges among colleagues and students. The bureaucratic and hierarchical educational administrative structures of both the public and private sector HEIs within Pakistan are often characterized by control, authority, favoritism and controlled communication system at all levels. Interviewee 4 said, we work according to the given guidelines by authorities, from where does our emotions come here? No place for them. Interviewee 5 said, decisions are taken in the larger interest of the institution. Institutional goals are kept in mind at all times. Thoughtful actions and decisions are required. Emotionality of leaders may harm decision making. In addition, Interviewee 10 said, no matter how emotional I get to my staff, I have to listen to my authorities. Decisions are made by them, not $m e$. In every act and decision, emotions are involved and compel the educational leaders to take the action or decision accordingly in the interest of the institution. The process through which educational leaders use their emotions for their institutional functioning provides them opportunities for personal and professional growth. The emotionality of the educational leaders helps them in understanding the situations and requirements of the institutions more diligently and take the right decision rationally in the interest of the institution. The participants showed promotion of rationalist approach within goal orientation, human relations and decision making approaches. Emotional instances and emotionality are not much appreciated by the study participants.

HEIs support the idea that ideal professionalism is more rational and mechanical than emotional. In order to maintain a professional and appropriate decorum, the educational leaders continuously deny or suppress the involvement and expressions of emotions in their professional life. In both public and private sector universities of Sindh, it has been reported by a few participants that educational leaders avoid sharing ideas, events and feelings about ongoing processes and problems and cover them with mechanics required for running the institutions. Educational leaders within universities in Sindh come across many situations where they tend to be emotional about something- a task, an assignment, colleagues, students or authorities- and consider their issues rather rationally or irrationally depending upon its nature and intensity. The destruction attached with their emotionality or use of emotions for institutional functioning approaches comes, when they tend to be more emotional, but not irrational. There are many situations within both public and private sector universities of Sindh, in which educational leaders' emotions undermine reasoning and lead to pure irrationality. Under situations when educational leaders' emotions get combined with irrationality, destruction to the institution occurs.

In both the public and private sector universities of Sindh, educational leaders enjoy power and authority over their colleagues and pretends to be rationalist and mechanical hiding their emotional sides to suppress the colleagues. In Sindh's university context, it is rare to find the acceptance of emotional interchanges among Educational Leaders and colleagues. In almost all the responses which the Educational Leaders have shared, nearly 
everyone from executive, administrative or operative levels have highlighted the importance of emotionalism, but shown preference for rationalistic and mechanistic approaches to institutional functioning. The bureaucratic and hierarchical educational administrative structures of both the public and private sector universities within Sindh are often characterized by control, authority, favoritism and controlled communication systems at all levels.

\section{Educational Leaders' Perceived and Displayed Emotions}

Educational leaders' emotional labour creates problems for them and their colleagues when the nature of the work they do requires them to display emotions that are inconsistent with their real feelings. These are frequently occurring situations for educational leaders within institutions in their day to day tasks. There are people with whom the educational leaders have to work, although they find it difficult to be friendly with such colleagues. Irrespective of any odds attached with the colleagues that the educational leaders have to work with, their job requires to interact with them on a regular basis. Perceived and displayed emotions are often different. Effective educational leaders within institutions are expected to perform their roles as per the demands and situations which mask their true emotional feelings and behaviours.

Educational leaders within institutions differ widely in terms of their emotional strategies that they display to boost the performance of their colleagues and staff. Some educational leaders view their emotional displays as a hindrance, while some others find them useful. Educational leaders who display their emotions appropriately to communicate, or who demonstrate better knowledge of their own emotions and those of their colleagues, are argued to perform at a higher level (Steyn \& Grant, 2007).

For perceived and displayed emotions of leaders, emotional dissonance is an expected trait and they are bound to display what they do not perceive. What educational leaders actually felt and perceived, is not something they are allowed to project. There are many barriers that hinder the way they display different emotions than what they experience. The educational institutions are places that are run under strict by laws, rules and regulations. Any drift from the regulations may cause heavy damage to the institution in many capacities

\section{State of Emotional Denial}

The state of emotional denial in decision making processes is the third identified theme in this study. According to educational leaders, there is no emotional inclination towards an idea and people. Rationalist and objective approach is to be adopted and an evidencebased approach is needed in decision making. Different perspectives need to be thought of in decision making while putting the emotions aside. Educational leaders are of the viewpoint that no emotions are involved in the institution or department in which they work. There is a systematic process based on rules and regulations. There is no place for their emotional display within the functions and processes of institution, as the decisions are to be based on facts and figures, and evidence. In the words of Interviewee 2, as being 
emotional beings, even in decision making we do have some emotional inclinations towards one idea or the other. However, I am quite clear that whenever it comes to decision making, we have to have as much of a rational approach as possible rather than emotional approach because institutions cannot afford to be emotional. Decisions cannot be taken based on personal likes and dislikes; rather they are to be taken in the best interests of the institution. Interviewee 5 shared his point of view saying that I dont think emotions should be involved during decision making. There are more chances of error when decisions are made on emotional instincts. Emotional involvement should not be there.

Interviewee 4 said as far as emotions are concerned, we do not have any emotions at all in the department where we work as a leader. We do everything in the department based on facts and figures and try to deal with them accordingly. In the views of Interviewee 6, although they are least required, they surely influence the work at various levels. People are working and they have a strong sense of emotions. While working, emotions are definitely used, however, a good leader always tries to avoid using emotions at work more on professional lines. For Interviewee 7 , emotions are important, but in the professional environment they are not much needed.

The educational leaders who showed any signs of emotions were seen as soft and would be taken advantage of by the colleagues. To be successful, educational leaders need to be hard-core, for which they need to deny or repress their own feelings while ignoring the feelings of their colleagues. Educational leaders, who know when they are upset, anxious or fearful, can relate better to others who are experiencing the same. This helps the leader to be able to handle disagreements, so that they don't grow into big conflicts. The leaders, who knows and recognizes their own emotions, can build better rapport with employees or followers. This rapport leads to better teamwork and productivity.

Educational leaders are in emotional denial because they take it as a coping mechanism that gives them time to adjust the distressing situation they are in within their educational institutions. During the state of emotional denial, they try to protect themselves by refusing to accept the truth about the situation, the task or the decision. Instead they pretend as if nothing affects them and their progress at the institutions.

\section{Behaviorist and Humanist Emotions of Leaders within Institutions}

The educational leaders repeatedly use the reference of humanist and behaviourist philosophies in response to their emotionality within institutions. A few of the educational leaders shared that they feel satisfaction and contentment when humanistic approach is used by them in their institutions. According to them, when their colleagues are happy, they perform better. Educational Leaders shared some elements which they considered important for humanism in their institution. Counselling is taken as an important part of humanistic emotions of leaders. Human considerations, positive encouragement, faith and trust upon colleagues and staff, distribution or delegation of work and responsibilities according to colleagues' potentials, and avoiding favoritism are important components of humanism. Humanistic emotions' display require specific skills and techniques for management within institutions.

Contrary to humanistic emotions, most of the educational leaders shared that the use of behaviourist emotional display in the institutions according to the need and situation 
demotivates the colleagues. There seems to be an unnecessary delay in the completion of tasks by the colleagues, when the leader puts off the humanist emotions and sets deadlines to meet the targets. According to educational leaders, behaviourist emotions do not permit them to develop personal relations with their colleagues or let their personal emotions affect their decisions or the set deadlines. Institutions work more mechanically when leaders apply behaviourist philosophy within their institutions.

In the words of Interviewee 8, I go for a more humanistic approach in the organization. I feel satisfied. Interviewee 2 stated that when you respect your colleagues, when they share difficulties with you, I try to make them satisfied by my way of talking. I think the basic principles are the same to make people happy - listening to their problems, respecting them, involving them in the decision making process, helping them realize that they are important part of the organization and their cooperation is important for smooth functioning of the institution and in the accomplishment of goals. Equality, justice, equity and fairness are also important elements of joy to a leader. In Interviewee 3's point of view, I believe you can get the people to do the right things if you can counsel them. I have done this experiment many times in trying to bring my colleagues on the right path. Interviewee 9 stated that you have to positively encourage the staff to work. You have to have a kind of trust upon them, because this is the responsibility of the leader to develop faith and trust among his/her colleagues. The staff working with you should also have the capability and leadership qualities like you in the organization.

A few of the educational leaders believed that to have effective institutional functioning, humanistic approach works better than behaviourist approach, as the humanistic approach emphasizes on the improvement of the whole individuals and their emotional reactions, whereas behaviours and feelings are related to the self. Educational leaders, while using humanistic approach, operate on the basic assumptions for their colleagues that they are individuals who have a free will and have a desire to make themselves, their colleagues and their institutions a better place to work.

Humanistic emotions displayed by the leaders play a double edged role in the institutional functioning. They do not only boost the morale of colleagues and staff, but also make the leader satisfied. When the leaders respect their colleagues, give them a feeling of ownership, listen to their problems, involve them in the decision making process, help them realize that they are important part of the organisation and their cooperation is important for the smooth functioning and the accomplishment of goals, positively encourage them to work and counsel them, they promote healthy institutional functioning. Equality, justice, equity and fairness are important displays of humanist emotions of a leader within an institution.

\section{Programmed and Controlled Emotions of Educational Leaders within Institutions}

Educational leaders shared their views on programmed and controlled emotions within their institutions. According to them, their emotional display in their institutions is based on situations and tasks where they have programmed and controlled emotions at a disclosure. According to them, present-mindedness leads to the skill of controlling their minds and emotions according to situations.

In the words of Interviewee 5, a leader is present-minded. Besides being present-minded, 
he also possess the skill of controlling his mind. While controlling his mind he is actually controlling his emotions. With respect to the nature of people in the organization, the leader uses his emotions according to them. Educational leaders' situational and programmed emotions are displayed according to people, work environment and task.

According to the data, it was experienced by the educational leaders that the programmed and controlled emotions they display as per situations had been advantageous for their institutions. It helps them in planning their emotional responses to varied situations before their occurrence.

Educational leaders further stated that their emotional display in their institutions are divided into two categories of personal emotional display and professional emotional display. The programmed and controlled emotions are mainly the professional emotional display which is expected by their institution. The programmed emotions of leaders are also labelled as professional emotions which are considered to be more creative, situational and rational in approach. Interviewee 9 shared her experience of controlling her emotions in the following words 'I believe that my controlled emotions help me a lot in my institution. I have trained myself in a way that whenever situations go against me, I plan my reactions accordingly and then deal with them. It gives me pleasure that even in situations where people had been very insulting and abusive to me, I dealt with them in a very controlled manner. I did not react the way the other person wanted me to. However, I regulated my emotions accordingly'.

The notion of programmed and controlled emotions has also been highlighted by the educational leaders. Based on their perception, educational leaders are present-minded and possess the skills of controlling their minds and emotions. With respect to the nature of people in the institutions, they use the respective emotions to get the work done. Other than this, they are also task-oriented and person-oriented. When it comes to relations within an institution, they become person-oriented, and when it comes to goalorientation or decision making, they shift to task-orientation. Irrespective of being either person-oriented or goal-oriented, a leader displays programmed emotional stimuli to the colleagues keeping in view the needs and requirements of the people working as well as the task assigned.

Interviewee 1 highlighted his understanding of controlled emotions in the following words, once you have a policy decision to implement, it has to be broken down into tasks. Those tasks are to be assigned in tiers of judgment of your emotional readings. To whom you assign these tasks becomes very important. The task must be assigned to the person based on your judgment of the potential and capacity of the individual to perform the task. So, your readings of his emotions and your emotions in perceiving that person are of great relevance and importance.

Programming of emotions and controlling of emotions are important skills which the educational leaders need to develop among themselves. It has been quoted by respondents of both the public and private sector universities in Sindh that those educational leaders who lack emotional control do not remain in their leadership positions for long. For educational leaders, being emotionally aware of themselves and their colleagues is an important trait which they need to possess as their job is not easy. As the nature of their job is tough, it is expected that the outcomes of their acts and decisions done or taken are based on rational stimuli rather than emotional one. Displaying emotional control and 
programming is something that is required by them and they are expected to programme their emotions as per situations at hand to continue their career and enhance institutional functioning.

\section{Limitations}

One of the limitations of the study is that it is highly selective. By definition and procedure, only those studies were reviewed that focus on the effect of emotions on different processes and levels of institutional functioning. The narrow focus helped in outlining the determinants of this study by leaving out many themes that could have been added. Another limitation of this study is that it only investigated the role of leaders' emotions in institutional functioning and did not incorporate the other elements of psychodynamics in leadership in the study.

\section{Conclusion}

This study investigated the role of the educational leaders' emotions in the institutional functioning of public and private sector higher education institutes. The qualitative data were collected through semi-structured interviews and the thematic analysis produced five major themes. The discussions on the themes were made keeping the psychological, social, emotional and political aspects of leadership and institutional functioning in mind. The arguments in the discussion of the qualitative themes are made on the grounds that educational leaders' emotions are part of their being which they carry all the time. Their emotions have been marginalized and considered as barriers in the process of effective institutional functioning. Rationality is given preference over emotionality and its utilization is considered to be a problem. However, educational leaders' emotions are involved in every process and function of the institution where the educational leaders work, so the awareness of their own emotions and effective control and expression of their emotions are integral to successful leadership in HEIs. 


\section{References}

Aguilera-Ontiveros, A., \& Contreras-Manrique, J. C. (2006). The role of emotions in organizational join decisions: A formal modeling framework. In Proceedings of The First World Congress on Social Simulation, 1(1), 351-358.

Almohammad, A. H. (2016). Toward a theory of political emotion causation. Sage Open, $6(3), 1-23$.

Arias, J. T., Higuita, J. C., \& Castrilln, O. D. (2010). The relationship between leadership and personality. Cuadernos de Admnistracion, 23(41), 81-105.

Berezin, M. (2002). Secure states: Towards a political sociology of emotion. The Sociological Review, 50(2), 33-52.

Bottoms, G., \& Schmidt-Davis, J. (2010). The three essentials: Improving schools requires district vision, district and state support, and principal leadership. Southern Regional Education Board (SREB).

Bradbury-Jones, C., Coleman, D., Davies, H., Ellison, K., \& Leigh, C. (2010). Raised emotions: A critique of the Peshkin approach to reflection. Nurse Education Today, 30(6), 568-572.

Durlak, J. A., Weissberg, R. P., Dymnicki, A. B., Taylor, R. D., \& Schellinger, K. B. (2011). The impact of enhancing students' social and emotional learning: A meta-analysis of school-based universal interventions. Child Development, 82(1), 405-432.

Fisher, P., \& Byrne, V. (2012). Identity, emotion and the internal goods of practice: A study of learning disability professionals. Sociology of Health $\mathcal{E}$ Illness, 34(1), 79-94.

Foo, M.-D. (2011). Emotions and entrepreneurial opportunity evaluation. Entrepreneurship Theory and Practice, 35(2), 375-393.

Fotaki, M., Long, S., \& Schwartz, H. S. (2012). What can psychoanalysis offer organization studies today? Taking stock of current developments and thinking about future directions. Organization Studies, 33(9), 1105-1120.

Fraenkel, J. R., Wallen, N. E., \& Hyun, H. H. (1993). How to design and evaluate research in education. McGraw-Hill: New York.

Franz, M. (2015). Will to love, will to fear: The emotional politics of illegality and citizenship in the campaign against birthright citizenship in the US. Social Identities, 21(2), 184-198.

Greyvenstein, H., \& Cilliers, F. (2012). Followership's experiences of organisational leadership: A systems psychodynamic perspective. SA Journal of Industrial Psychology, $38(2), 1-10$.

Groenendyk, E. (2011). Current emotion research in political science: How emotions help democracy overcome its collective action problem. Emotion Review, 3(4), 455-463.

Herre, C. (2010). Promoting team effectiveness: How leaders and learning processes influences team outcomes.

Koval, P., Butler, E. A., Hollenstein, T., Lanteigne, D., \& Kuppens, P. (2015). Emotion regulation and the temporal dynamics of emotions: Effects of cognitive reappraisal and expressive suppression on emotional inertia. Cognition and Emotion, 29(5), 831851. 
Namkoong, K., Fung, T. K., \& Scheufele, D. A. (2012). The politics of emotion: News media attention, emotional responses, and participation during the 2004 US presidential election. Mass Communication and Society, 15(1), 25-45.

Shen, L., Wang, M., \& Shen, R. (2009). Affective e-learning: Using "emotional" data to improve learning in pervasive learning environment. Journal of Educational Technology $\mathcal{E}$ Society, 12(2), 176-189.

Srivastava, S., Tamir, M., McGonigal, K. M., John, O. P., \& Gross, J. J. (2009). The social costs of emotional suppression: A prospective study of the transition to college. Journal of Personality and Social Psychology, 96(4), 883-897.

Steyn, M. E., \& Grant, T. (2007). "A real bag of mixed emotions": Re-entry experiences of South African exiles. International Journal of Intercultural Relations, 31(3), 363-389.

Thiel, C. E., Connelly, S., \& Griffith, J. A. (2012). Leadership and emotion management for complex tasks: Different emotions, different strategies. The Leadership Quarterly, 23(3), 517-533.

Wright, S. (2012). Emotional geographies of development. Third World Quarterly, 33(6), 1113-1127. 